Article

\title{
Comparison of the Sulfonamide Inhibition Profiles of the $\alpha$-Carbonic Anhydrase Isoforms (SpiCA1, SpiCA2 and SpiCA3) Encoded by the Genome of the Scleractinian Coral Stylophora pistillata
}

\author{
Sonia Del Prete $\left.{ }^{1}{ }^{(}\right)$, Silvia Bua ${ }^{2}{ }^{\circ}$, Fatmah A. S. Alasmary ${ }^{3}$, Zeid AlOthman ${ }^{3}{ }^{\circ}$, \\ Sylvie Tambutté ${ }^{4}$, Didier Zoccola ${ }^{4, *}$, Claudiu T. Supuran ${ }^{2,3(1)}$ and Clemente Capasso ${ }^{1, *(1)}$ \\ 1 Istituto di Bioscienze e Biorisorse, National Research Council (CNR), Via Pietro Castellino 111, \\ 80131 Napoli, Italy; sonia.delprete@ibbr.cnr.it \\ 2 Dipartimento Neurofarba, Sezione di Scienze Farmaceutiche e Nutraceutiche, Università degli Studi di \\ Firenze, Via U. Schiff 6, 50019 Sesto Fiorentino, Florence, Italy; silvia.bua@unifi.it (S.B.); \\ claudiu.supuran@unifi.it (C.T.S.) \\ 3 Department of Chemistry, College of Science, King Saud University, \\ P.O. Box 2455 Riyadh 11451, Saudi Arabia; fasmari@ksu.edu.sa (F.A.S.A.); zaothman@KSU.EDU.SA (Z.A.) \\ 4 Department of Marine Biology, Centre Scientifique de Monaco, 8 Quai Antoine 1, 98000 Monaco, Monaco; \\ stambutte@centrescientifique.mc \\ * Correspondence: zoccola@centrescientifique.mc (D.Z.); clemente.capasso@ibbr.cnr.it (C.C.); \\ Tel.: +377-97-774470 (D.Z.); +39-081-6132559 (C.C.)
}

Received: 12 February 2019; Accepted: 26 February 2019; Published: 1 March 2019

\begin{abstract}
The ubiquitous metalloenzymes carbonic anhydrases (CAs, EC 4.2.1.1) are responsible for the reversible hydration of $\mathrm{CO}_{2}$ to bicarbonate $\left(\mathrm{HCO}_{3}{ }^{-}\right)$and protons $\left(\mathrm{H}^{+}\right)$. Bicarbonate may subsequently generate carbonate used in many functional activities by marine organisms. CAs play a crucial role in several physiological processes, e.g., respiration, inorganic carbon transport, intra and extra-cellular $\mathrm{pH}$ regulation, and bio-mineralization. Multiple transcript variants and protein isoforms exist in the organisms. Recently, $16 \alpha$-CA isoforms have been identified in the coral Stylophora pistillata. Here, we focalized the interest on three coral isoforms: SpiCA1 and SpiCA2, localized in the coral-calcifying cells; and SpiCA3, expressed in the cytoplasm of the coral cell layers. The three recombinant enzymes were heterologously expressed and investigated for their inhibition profiles with sulfonamides and sulfamates. The three coral CA isoforms differ significantly in their susceptibility to inhibition with sulfonamides. This study provides new insights into the coral physiology and the comprehension of molecular mechanisms involved in the bio-mineralization processes, since CAs interact with bicarbonate transporters, accelerating the trans-membrane bicarbonate movement and modulating the $\mathrm{pH}$ at both sides of the plasma membranes.
\end{abstract}

Keywords: carbonic anhydrases; sulfonamides; CA isoforms; biomineralization; corals CAs; recombinant enzyme

\section{Introduction}

Coral reef architecture comes from the deposition of massive calcium carbonate skeletons secreted by scleractinian corals, or hard corals [1]. These corals represent the habitat for a vast diversity of organisms [2]. They live in intimate symbiosis with unicellular dinoflagellate symbionts, commonly called zooxanthellae, which are hosted in the coral tissues. The enzymes carbonic anhydrases (CAs, EC 4.2.1.1) play major roles in two essential processes of coral's physiology; they are involved in the carbon supply for calcium carbonate precipitation (formation of skeletons) as well as in carbon-concentrating 
mechanisms for symbiont photosynthesis [3]. Numerous studies have shown CAs are ubiquitous metallo-enzymes, which are responsible for the reversible hydration of $\mathrm{CO}_{2}$ to bicarbonate $\left(\mathrm{HCO}_{3}{ }^{-}\right)$, carbonate $\left(\mathrm{CO}_{3}{ }^{2-}\right)$, and protons $\left(\mathrm{H}^{+}\right)[2,4-15]$. In the biological systems, the $\mathrm{CO}_{2}, \mathrm{HCO}_{3}{ }^{-}, \mathrm{CO}_{3}{ }^{2-}$, and $\mathrm{H}^{+}$are interconnected by equilibrium reactions, and their concentrations are regulated by $\mathrm{CAs}[5,16-19]$. Thus, these enzymes play a crucial role in several physiological processes such as respiration, inorganic carbon transport, intra and extra-cellular $\mathrm{pH}$ regulation, or the bio-mineralization process [20-24]. Up to the present time, seven polyphyletic classes of CAs have been described and indicated with the Greek letters $\alpha, \beta, \gamma, \delta, \zeta, \eta$ and $\theta[19,25-27]$. Moreover, members of each class possess multiple transcript variants and protein isoforms, which are characterized by different biochemical properties and have specific tissue/organ and sub-cellular localizations [4,5,17,28-31]. For examples, CAs present in animals belong to $\alpha$-class [32,33], plants and algae have $\alpha-, \beta-, \gamma-, \delta$ - and $\theta$-classes; fungi encode for $\alpha$ and $\beta$-CAs; protozoa for $\alpha-, \beta$ - and/or $\eta$-CAs; bacteria for $\alpha-, \beta$ - and $\gamma$-CA classes [30,31,34-38]. Intriguing, in the oyster Pinctada fucata a matrix protein, called nacrein, has been identified. It participates in the formation of the nacreous layer and is characterized by a CA domain present at the $\mathrm{N}$-terminus part of the polypeptide sequence [39]. In mammals, $16 \alpha$-CA isoforms have been identified: Eight of them are cytosolic, five are membrane-bound, two are mitochondrial, and only one is secreted, the last three being devoid of catalytic activity and referred to as CA Related Proteins (CARPs) $[16,18,27]$.

In corals, most of the available results on CAs were obtained by measuring the CA activity in crude tissue extracts using non-specific CA inhibitors or antibodies raised against human isoforms $[6,7,14,40,41]$. Recently, the development of molecular biology tools allowed the isolation and full characterization of several CA isoforms in different coral species, such as Lobactis scutaria [42], Stylophora pistillata [2,8], and Acropora millepora [43]. In particular, our groups analyzing the molecular data in the branching coral Stylophora pistillata identified $16 \alpha$-CA isoforms in the transcriptome and genome of this scleractinian coral [2,3,8,44-48]. Among them, two $\alpha$-CAs were isolated (STPCA and STPCA-2, here, indicated as SpiCA1 and SpiCA2, respectively) and have been localized in the coral-calcifying cells, within the epithelium facing the skeleton [2,8]. It has been proposed that SpiCA1 catalyzes the inter-conversion between the different inorganic forms of dissolved inorganic carbon at the site of calcification, whereas SpiCA2 is an intracellular enzyme, which is found as an organic matrix protein incorporated in the skeleton $[49,50]$. Recently, a novel $\alpha-C A$, named SpiCA3, which is cytoplasmic and ubiquitously expressed in all the coral cell layers, has been characterized [20]. This isoform showed a catalytic activity 1.14-times higher than human CA II and is one of the most effective $\mathrm{CO}_{2}$ catalysts among all CAs known to date with a $\mathrm{k}_{\text {cat }}$ of $1.6 \times 10^{6} \mathrm{~s}^{-1}$ and a $\mathrm{k}_{\text {cat }} / \mathrm{K}_{\mathrm{M}}$ of $1.5 \times 10^{8} \mathrm{M}^{-1} \mathrm{~s}^{-1}$ [20]. Intriguingly, the three coral CAs (SpiCA1, SpiCA2, and SpiCA3) differ significantly in their catalytic activity and susceptibility to inhibition with anions [20]. Here, the sulfonamide inhibition profile of the SpiCA3 has been investigated for the first time. Sulfonamides and their bio-isosteres represent the most important class of CA inhibitors (CAIs). Furthermore, the SpiCA3 inhibition profile was compared with those obtained for SpiCA1 and SpiCA2 previously studied by our groups [45].

\section{Results and Discussion}

\subsection{Recombinant Enzymes}

The recombinant SpiCA1, SpiCA2, and SpiCA3 were obtained, as described earlier [2,20,44,51,52]. Figure 1 shows a multi-alignment of the three $\alpha$-CA isoforms encoded by the genome $S$. pistillata and investigated up until now. It is readily apparent that the three coral isoforms show the main features of a typical mammalian $\alpha$-CAs. They possess the conserved: (i) Three His ligands, which coordinate the Zn(II) ion crucial for catalysis, (His94, His96, and His119, hCA I numbering system); (ii) the two gate-keeping residues (Glu106 and Thr199), which are implicated in the substrate orientation and the binding of the inhibitors; and (iii) the proton shuttle residue (His64), which is involved in the 
transfer of the proton $\left(\mathrm{H}^{+}\right)$from the water coordinated to the $\mathrm{Zn}(\mathrm{II})$ ion to the environment, influencing and making very fast the rate of the catalytic reaction. Furthermore, SpiCA3, diversely from the other two coral isoforms, is a cytoplasmic protein. SpiCA1 and SpiCA2 are, in fact, secreted proteins characterized by the presence of a signal peptide at the $\mathrm{N}$-terminal of their amino acid sequences (see Figure 1). Interesting, the insertions and deletions of a relatively extended number of amino acid residues along the polypeptide chain, which affect the three coral isoforms (Figure 1), may influence the kinetic and inhibition behavior of the coral enzymes, probably because of significant alterations of their three-dimensional structure. For example, SpiCA3 showed a $\mathrm{k}_{\text {cat }}=10^{6} \mathrm{~s}^{-1}$, which is one order of magnitude higher than the $\mathrm{k}_{c a t}\left(10^{5} \mathrm{~s}^{-1}\right)$ of the other two isoforms.

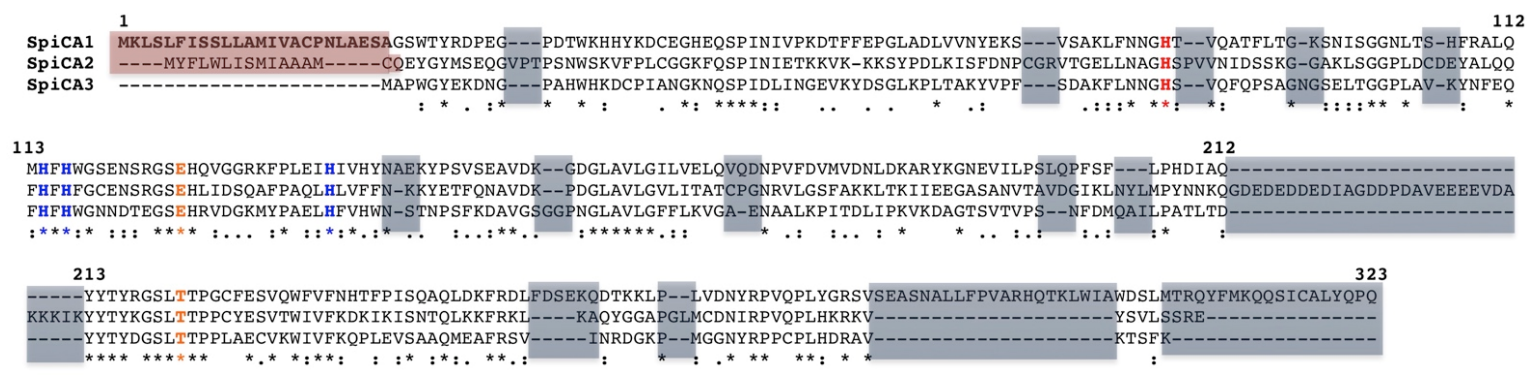

Figure 1. This Multiple amino acid sequence alignment of the $\alpha$-CAs encoded by the genome of S. pistillata (SpiCA1, SpiCA2, and SpiCA3). The main features of $\alpha$-CA are indicated with different colors: zinc ligands are in blue; the "gate-keeper" residues are in orange; the histidine proton shuttle is in red; long stretches of 31 and 35 amino acid residues, in black bold. The insertion or deletion of amino acid residues are indicated with the grey transparent boxes, while the signal peptides typifying the SpiCA1 and SpiCA2 isoforms are included in the red transparent box. The symbol $\left(^{*}\right)$ signifies identity at a position, while the symbols (:) and (.) designates conserved and semi-conserved substitutions, respectively. The SpiCA1 numbering system was used. The multiple sequence alignment was performed with the program Muscle Ver. 3.8. SpiCA1, S. pistillata isoform 1 (accession no. ACA53457.1); SpiCA2, S. pistillata isoform 2 (accession no. EU532164.1); and SpiCA3, S. pistillata isoform 3 (accession no. XP_022794253.1).

\subsection{Sulfonamide Used as CAIs}

As described in the literature, it has been demonstrated that the sulfonamide CA inhibitors (CAIs), such as acetazolamide or ethoxzolamide, drastically decrease the coral calcification rates, with inhibition of up to $73 \%$ [50]. These data suggest that the coral CAs are finely tuned in providing carbonate and $\mathrm{H}^{+}$ions for the control of the calcification process and $\mathrm{pH}$ homeostasis, respectively $[6,14,53,54]$. Unfortunately, very few studies are available on the inhibition of the CAs encoded by coral genomes. The CAIs can be clustered into several different groups considering their binding mode to the enzyme active site [29,55]: (1) The metal ion binders (anion, sulfonamides and their bioisosteres, dithiocarbamates, xanthates, etc.); (2) compounds which anchor to the zinc-coordinated water molecule/hydroxide ion (phenols, polyamines, thioxocoumarins, sulfocumarins); (3) compounds occluding the active site entrance, such as coumarins and their isosteres; (4) compounds binding out of the active site, such as an aromatic carboxylic acid derivative; and (5) inhibitors with an unknown binding mechanism, such as secondary/tertiary sulfonamides, protein tyrosine kinase inhibitors, and fullerenes, for which the X-ray crystallographic structure is unavailable [29]. The most investigated CAIs are the anions and the sulfonamides [19,29,56,57]. A library of 40 compounds, 39 primary sulfonamides, and one sulfamate, were used as CAIs (Figure 2). Derivatives 1-24 and AAZ-HCT are either simple aromatic/heterocyclic sulfonamides widely used as building blocks for obtaining new families of such pharmacological agents, or they are clinically used agents, among which acetazolamide (AAZ), methazolamide (MZA), ethoxzolamide (EZA), and dichlorophenamide (DCP) are the classical, systemically acting antiglaucoma CAIs. Dorzolamide (DZA) and brinzolamide 
(BRZ) are topically acting antiglaucoma agents; benzolamide (BZA) is an orphan drug belonging to this class of pharmacological agents.

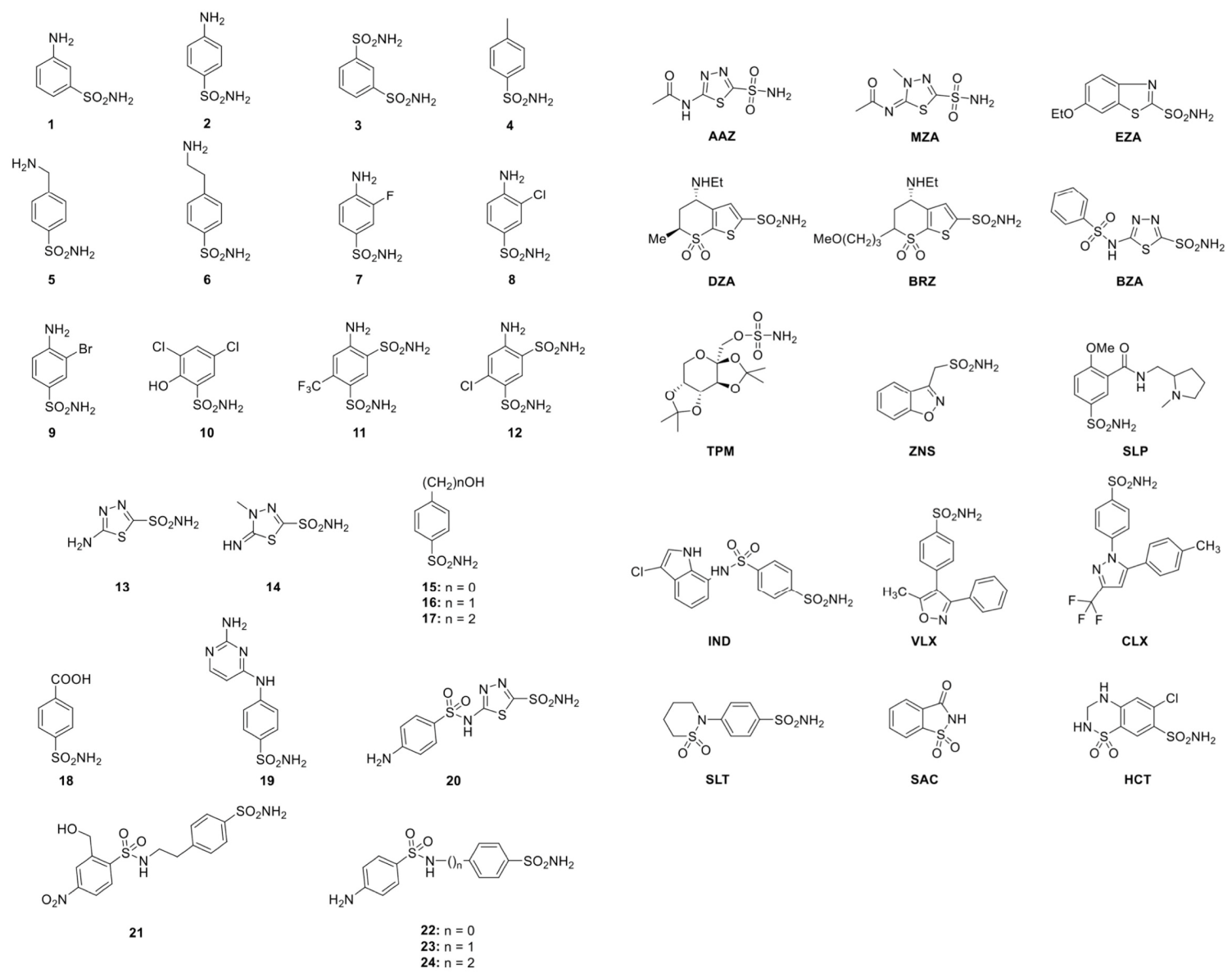

Figure 2. 38 sulfonamides and one sulfamate (Topiramate (TPM)) used for studying the inhibition profile of the three coral isoforms (SpiCA1, SpiCA2, and SpiCA3).

Moreover, the zonisamide (ZNS), sulthiame (SLT), and the sulfamic acid ester topiramate (TPM) are widely used antiepileptic drugs. Sulpiride (SLP) and indisulam (IND) were also shown by our group to belong to this class of pharmacological agents, together with the COX2 selective inhibitors celecoxib (CLX) and valdecoxib (VLX). Saccharin (SAC) and the diuretic hydrochlorothiazide (HCT) are also known to act as CAIs. As shown in Figure 3, sulfonamides, such as the clinically used derivatives acetazolamide, methazolamide, ethoxzolamide, dichlorophenamide, dorzolamide, and brinzolamide, bind in a tetrahedral geometry to the $\mathrm{Zn}(\mathrm{II})$ ion in the deprotonated state, with the nitrogen atom of the sulfonamide moiety coordinated to $\mathrm{Zn}(\mathrm{II})$ and an extended network of hydrogen bonds, involving amino acid residues of the enzyme, also participating in the anchoring of the inhibitor molecule to the metal ion $[19,29,55,58]$. The aromatic/heterocyclic part of the inhibitor interacts with the hydrophilic and hydrophobic residues of the catalytic cavity (Figure 3) $[19,29,56,57]$. 


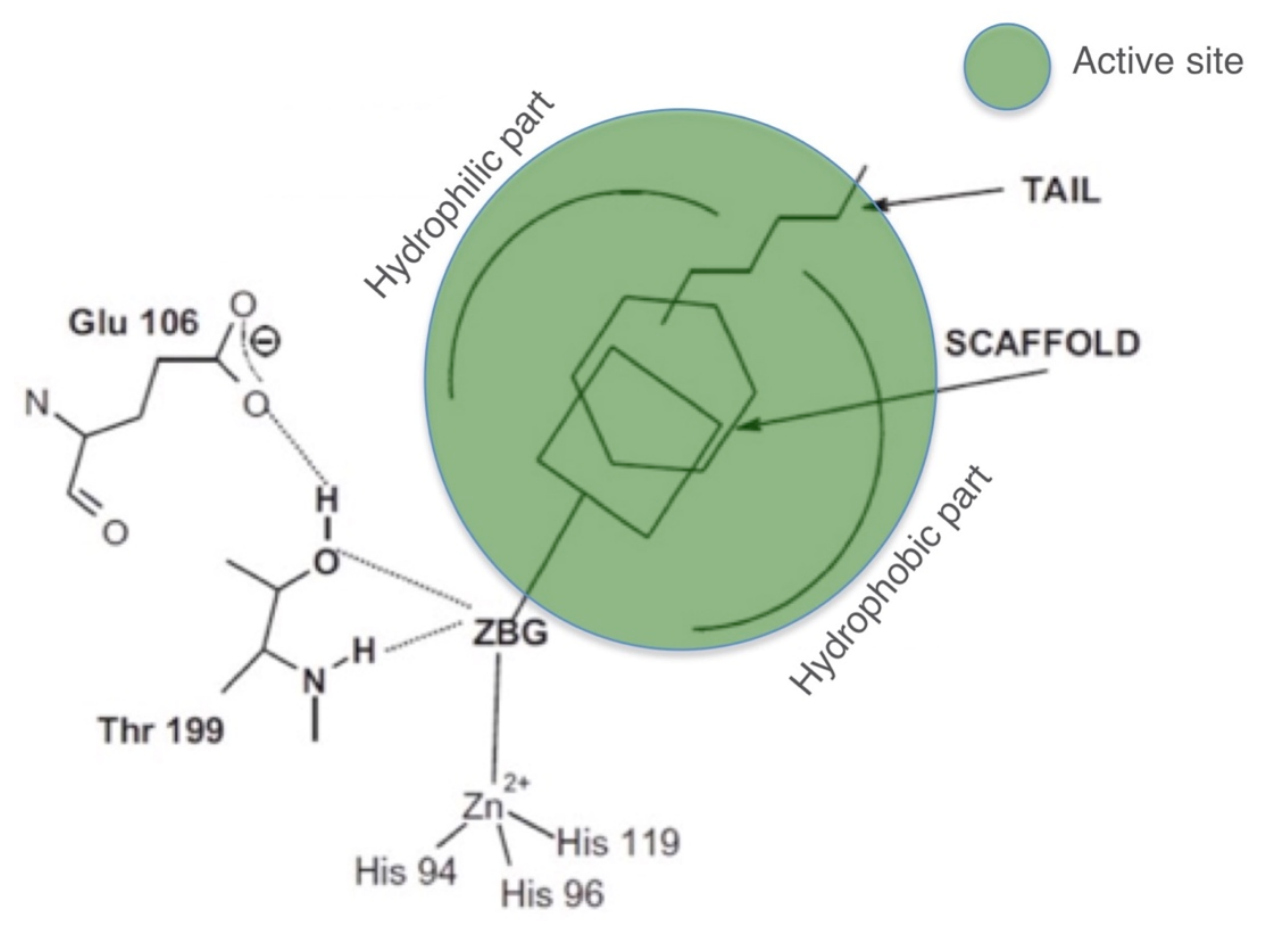

Figure 3. Schematic representation of the metal binding mode of CAIs to human (h) CA isoform hCA II, such as sulfonamides and their bio-isosters.

\subsection{CA Inhibition Data and Comparative Analysis}

Table 1 shows inhibition data of sulfonamides (and one sulfamate, TPM) against the human $\alpha$-CAs (isoforms hCA I and hCA II) and the recombinant coral $\alpha$-CA isoforms (SpiCA1, SpiCA2, and SpiCA3). Recently, our groups reported data for hCAI, hCAII, SpiCA1, and SpiCA2 earlier [8,45]. The following should be noted regarding the inhibition of the three coral enzymes with the compounds investigated in this study:

(i) High potency inhibitors

Most of the tested sulfonamides were effective inhibitors of the coral isoform SpiCA1 with a $\mathrm{K}_{\mathrm{i}}$ in the range of 16-92 $\mathrm{nM}$. This is the case of the compounds 5, 7, 8, 14, 18, 19, 20, AAZ, MZA, EZA, DZA, BRZ, BZA, TMP, VLX, CLX, SLT, and SAC. Intriguingly, the majority of these compounds were moderate inhibitors of SpiCA2 and SpiCA3 showing a $\mathrm{K}_{\mathrm{I}}>100 \mathrm{nM}$. The SpiCA2 inhibition profile showed only one compound (AAZ) with a $\mathrm{K}_{\mathrm{I}}<100 \mathrm{nM}$; while SpiCA3 was well inhibited by compounds 17, 19, 20, 21, 23, 24, and IND.

(ii) Medium potency inhibitors

A large number of simple aromatic sulfonamides, such as derivatives 2-20, and the pharmacological sulfonamides AAZ, MZA, EZA, DZA, BRZ, BZA, ZNS, TMP, SLP, IND, CLX, SLT, and SAC showed moderate SpiCA2 inhibitory properties with a $\mathrm{K}_{\mathrm{I}}$ in the range $105-868 \mathrm{nM}$. Intriguing, the sulfonamide inhibition profile of SpiCA2 was characterized mainly by moderate inhibitors (Table 1 ). The compounds, which resulted in effective and moderate inhibitors of SpiCA1 or moderate inhibitors of SpiCA2, such as 2, 5, 6, 7, 8, TMP, ZNS, SLP, CLX, and SAC resulted in the worst inhibitors for the coral isoform SpiCA3. The majority of these derivatives are benzenesulfonamides with one or two simple substituents in ortho, para, or the 3,4-positions of the aromatic ring with respect to the sulfamoyl zinc-binding moiety.

(iii) Ineffective inhibitors

A large number of sulfonamides, such as derivatives 1, 2, 5, 6, 7, 8, 10, TPM, ZNS, SLP, VLX, CLX, and SAC were weak inhibitors of SpiCA3 showing a $\mathrm{K}_{\mathrm{i}}>1000 \mathrm{nM}$. Interesting, the coral isoform 
SpiCA2 showed only one ineffective derivative (VLX), while the SpiCA1 was the isoform better inhibited by all the compounds used in the present study.

(iv) Human isoforms versus coral enzymes

The comparison of the inhibition profile of the human isoforms with those of the coral enzymes showed that SpiCA1 resulted very similar to the isoform hCAII. Furthermore, the isoform hCAI was not inhibited by most of the derivatives indicated with the numbers 1, 2, and those of the range 4-17 $\left(K_{\mathrm{I}}>1000 \mathrm{nM}\right)$. Moreover, the clinically used agents, among which DZA, BRZ, and CLX didn't affect the hCAI activity, while they were high potency inhibitors for hCAII and SpiCA1 and low potency inhibitors for SpCA2 and SpiCA3.

Table 1. Inhibition of human $\alpha$-CAs (hCA I and hCA II) and the three recombinant enzyme from S. pistillata (SpiCA1, SpiCA2, and SpiCA3) with sulfonamides 1-24 and the clinically used drugs AAZ-HCT reported in Figure 2.

\begin{tabular}{|c|c|c|c|c|c|}
\hline \multirow{2}{*}{ Inhibitor } & \multicolumn{5}{|c|}{$K_{I} *(n M)$} \\
\hline & hCA I $^{a}$ & hCA II ${ }^{a}$ & SpiCA1 $^{a}$ & SpiCA2 ${ }^{a}$ & SpiCA3 \\
\hline 1 & 28,000 & 300 & - & - & 5059 \\
\hline 2 & 25,000 & 240 & 364 & 300 & 4276 \\
\hline 3 & 79 & 8 & - & - & 667 \\
\hline 4 & 78,500 & 320 & 614 & 516 & 694 \\
\hline 5 & 25,000 & 170 & 83 & 508 & 7871 \\
\hline 6 & 21,000 & 160 & 94 & 577 & 7828 \\
\hline 7 & 8300 & 60 & 75 & 493 & 3318 \\
\hline 8 & 9800 & 110 & 88 & 551 & 1815 \\
\hline 9 & 6500 & 40 & 104 & 540 & 918 \\
\hline 10 & 7300 & 54 & - & - & 2532 \\
\hline 11 & 5800 & 63 & 367 & 481 & 856 \\
\hline 12 & 8400 & 75 & 295 & 840 & 430 \\
\hline 13 & 8600 & 60 & 105 & 361 & 275 \\
\hline 14 & 9300 & 19 & 92 & 357 & 578 \\
\hline 15 & 5500 & 80 & - & - & 487 \\
\hline 16 & 9500 & 94 & - & - & 199 \\
\hline 17 & 21,000 & 125 & 770 & 701 & 66 \\
\hline 18 & 164 & 46 & 30 & 661 & 241 \\
\hline 19 & 109 & 33 & 25 & 868 & 83 \\
\hline 20 & 6 & 2 & 28 & 333 & 74 \\
\hline 21 & 69 & 11 & - & - & 53 \\
\hline 22 & 164 & 46 & - & - & 568 \\
\hline 23 & 109 & 33 & - & - & 62 \\
\hline 24 & 95 & 30 & - & - & 46 \\
\hline AAZ & 250 & 12 & 16 & 74 & 737 \\
\hline MZA & 50 & 14 & 21 & 132 & 821 \\
\hline EZA & 25 & 8 & 39 & 105 & 56 \\
\hline DZA & 50,000 & 9 & 18 & 113 & 354 \\
\hline BRZ & 45,000 & 3 & 48 & 169 & 250 \\
\hline BZA & 15 & 9 & 20 & 214 & 394 \\
\hline TPM & 250 & 10 & 29 & 367 & 5828 \\
\hline ZNS & 56 & 35 & 259 & 645 & 5513 \\
\hline SLP & 1200 & 40 & 430 & 415 & $>10,000$ \\
\hline IND & 31 & 15 & 163 & 394 & 92 \\
\hline VLX & 54,000 & 43 & 29 & 5710 & 2918 \\
\hline CLX & 50,000 & 21 & 34 & 690 & 9102 \\
\hline SLT & 374 & 9 & 45 & 123 & 251 \\
\hline SAC & 18,540 & 5959 & 40 & 104 & $>10,000$ \\
\hline HCT & 328 & 290 & - & - & 243 \\
\hline
\end{tabular}

${ }^{*}$ Errors in the range of $5-10 \%$ of the reported data, from 3 different assays (data not shown) ${ }^{\text {a }}$ Human recombinant isozymes and coral recombinant isoforms, stopped flow $\mathrm{CO}_{2}$ hydrase assay method, from References 12 and 45.-means not tested. 


\section{Material and Methods}

\subsection{Isoform Expression and Purification}

The recombinant SpiCA1, SpiCA2, and SpiCA3 were obtained, as described earlier [2,20,44,51,52]. Briefly, the BL21 DE3 competent cells (Agilent) were transformed with the recombinant vectors containing one of the three coral isoforms, grown at $37^{\circ} \mathrm{C}$ and induced with $0.1 \mathrm{mM}$ IPTG. After $30 \mathrm{~min}, \mathrm{ZnSO}_{4}(0.5 \mathrm{mM})$ was added to the culture medium and cells were grown for an additional four $\mathrm{h}$. Then, cells were harvested and re-suspended in the following buffer: $50 \mathrm{mM}$ Tris/ $\mathrm{HCl}, \mathrm{pH} 8.0$, $0.5 \mathrm{mM}$ PMSF, and $1 \mathrm{mM}$ benzamidine. Subsequently, bacterial cells containing the overexpressed CAs were disrupted by sonication at $4{ }^{\circ} \mathrm{C}$ and centrifugated at $12,000 \times g$ for $45 \mathrm{~min}$. The resultant supernatant was loaded onto a His-select HF Nickel affinity column (GE Healthcare, dimension: $1.0 \times 10.0 \mathrm{~cm}$ ), equilibrated with $0.02 \mathrm{M}$ phosphate buffer $(\mathrm{pH}$ 8.0) containing $0.01 \mathrm{M}$ imidazole and $0.5 \mathrm{M} \mathrm{KCl}$ at a flow rate of $1.0 \mathrm{~mL} / \mathrm{min}$. The recombinant proteins were eluted from the column using $0.3 \mathrm{M}$ imidazole, and then, dialyzed against $50 \mathrm{mM}$ Tris/ $\mathrm{HCl}, \mathrm{pH} 8.3$.

\subsection{Amino Acid Sequence Analysis}

Multi-alignment of amino acid sequences was performed using the program MUSCLE (MUltiple Sequence Comparison by Log-Expectation, EMBL-EBI in Hinxton, Cambridge (UK) Version 3.8), a new computer program for creating multiple alignments of protein sequence [59].

\subsection{Enzyme Inhibition Profile}

An Applied Photophysics stopped-flow instrument (Leatherhead, Surrey (UK)) has been used for assaying the $\mathrm{CA}$ catalyzed $\mathrm{CO}_{2}$ hydration activity [60]. Phenol red (at a concentration of $0.2 \mathrm{mM}$ ) has been used as an indicator, working at the absorbance maximum of $557 \mathrm{~nm}$, with $20 \mathrm{mM}$ TRIS (pH 8.3) as buffer, and $20 \mathrm{mM} \mathrm{NaClO}_{4}$ (for maintaining constant the ionic strength), following the initial rates of the CA-catalyzed $\mathrm{CO}_{2}$ hydration reaction for a period of $10-100 \mathrm{~s}$. The $\mathrm{CO}_{2}$ concentrations ranged from 1.7 to $17 \mathrm{mM}$ for the determination of the kinetic parameters (by Lineweaver-Burk plots) and inhibition constants. For each inhibitor, at least six traces of the initial $5 \%-10 \%$ of the reaction have been used for determining the initial velocity. The un-catalyzed rates were determined in the same manner and subtracted from the total observed rates. Stock solutions of inhibitor (10-100 mM) were prepared in distilled-deionized water, and dilutions up to $0.01 \mathrm{mM}$ were done after that with the assay buffer. Inhibitor and enzyme solutions were preincubated together for $15 \mathrm{~min}$ at room temperature before assay, to allow for the formation of the E-I complex or the eventual active site-mediated hydrolysis of the inhibitor. The inhibition constants were obtained by non-linear least-squares methods using PRISM 3 and the Cheng-Prusoff equation, as reported earlier [61-63], and represent the mean from at least three different determinations. All CA isoforms were recombinant ones obtained in-house. All salts/small molecules were of the highest purity available, from Sigma-Aldrich (Milan, Italy).

\section{Conclusions}

In general, CAs are metalloenzymes integrated with a structural-functional complex of sequential enzymes [64-66] interconnected by metabolites produced from one catalyst and passed into the active site of another enzyme [64,65]. For example, CA isoforms interact with bicarbonate transporters increasing the local bicarbonate concentration, and thus, accelerating the transmembrane bicarbonate movement, and modulating the $\mathrm{pH}$ at both sides of the plasma membranes [64,66]. All these metabolic processes influence the coral physiology. Therefore, the study of the coral CA inhibition profiles may provide new insights to design experiments aimed at a better understanding of the molecular mechanisms involved in coral biomineralization and symbiosis. Furthermore, from the Table 1, it is readily apparent that the sulfonamide inhibition profile of the coral isoforms is substantially different from those of the cytosolic human isoforms, proving that it might be possible to design selective inhibitors using the scaffold of leads detected here for producing antiinfectives agents towards the 
pathogenic CAs [67]. The study of the inhibition profiles of new CAs, such as the coral ones, will give new advances in the synthesis of novel CAIs or in the modification/optimization of the existing inhibitors for making them more selective towards the pathogenic CAs.

Author Contributions: For S.D.P. performed the cloning, expression, and purification of the recombinant coral enzyme; S.B. performed all the inhibition assays; F.A.S.A. and Z.A. performed chemistry data analysis; D.Z contributed reagents and materials, analyzed the data and edited the manuscript; C.T.S. supervised the manuscript, S.T. and C.C. wrote, edited and supervised the manuscript.

Funding: This research was financed in part by a Distinguished Scientists Fellowship Programme (DSFP) of King Saud University, Riyadh, Saudi Arabia, and by the Government of the Principality of Monaco.

Conflicts of Interest: The authors declare no conflict of interest.

\section{References}

1. Moya, A.; Tambutte, S.; Tambutte, E.; Zoccola, D.; Caminiti, N.; Allemand, D. Study of calcification during a daily cycle of the coral Stylophora pistillata: Implications for 'light-enhanced calcification'. J. Exp. Biol. 2006, 209, 3413-3419. [CrossRef] [PubMed]

2. Moya, A.; Tambutte, S.; Bertucci, A.; Tambutte, E.; Lotto, S.; Vullo, D.; Supuran, C.T.; Allemand, D.; Zoccola, D. Carbonic anhydrase in the scleractinian coral Stylophora pistillata: Characterization, localization, and role in biomineralization. J. Biol. Chem. 2008, 283, 25475-25484. [CrossRef] [PubMed]

3. Bertucci, A.; Moya, A.; Tambutte, S.; Allemand, D.; Supuran, C.T.; Zoccola, D. Carbonic anhydrases in anthozoan corals-A review. Bioorg. Med. Chem. 2013, 21, 1437-1450. [CrossRef] [PubMed]

4. Supuran, C.T.; Capasso, C. Carbonic anhydrase from porphyromonas gingivalis as a drug target. Pathogens 2017, 6, 30. [CrossRef] [PubMed]

5. Supuran, C.T.; Capasso, C. An overview of the bacterial carbonic anhydrases. Metabolites 2017, 7, 56. [CrossRef] [PubMed]

6. Al-Horani, F.A.; Al-Moghrabi, S.M.; de Beer, D. The mechanism of calcification and its relation to photosynthesis and respiration in the scleractinian coral Galaxea fascicularis. Mar. Biol. 2003, 142, 419-426. [CrossRef]

7. Al-Moghrabi, S.; Goiran, C.; Allemand, D.; Speziale, N.; Jaubert, J. Inorganic carbon uptake for photosynthesis by the symbiotic coral/dinoflagellate association. II. Mechanisms for bicarbonate uptake. J. Exp. Mar. Biol. Ecol. 1996, 29, 309-322. [CrossRef]

8. Bertucci, A.; Tambutte, S.; Supuran, C.T.; Allemand, D.; Zoccola, D. A new coral carbonic anhydrase in stylophora pistillata. Mar. Biotechnol. 2011, 13, 992-1002. [CrossRef] [PubMed]

9. Furla, P.; Allemand, D.; Orsenigo, M.N. Involvement of h(+)-atpase and carbonic anhydrase in inorganic carbon uptake for endosymbiont photosynthesis. Am. J. Physiol. Regul. Integr. Comp. Physiol. 2000, 278, R870-R881. [CrossRef] [PubMed]

10. Goreau, T.F. Calcium carbonate deposition by coralline algae and corals in relation to their roles as reef-builders. Ann. N. Y. Acad. Sci. 1963, 109, 127-167. [CrossRef] [PubMed]

11. Isa, Y.; Yamazato, K. The distribution of carbonic anhydrase in a staghorn coral Acropora hebes (dana). Galaxea 1984, 3, 25-36.

12. Kingsley, R.J.; Watabe, N. Role of carbonic anhydrase in calcification in the gorgonian Leptogorgia virgulata. J. Exp. Zool. 1987, 241, 171-180. [CrossRef]

13. Leggat, W.; Marendy, E.M.; Baillie, B.; Whitney, S.M.; Ludwig, M.; Badger, M.R.; Yellowlees, D. Dinoflagellate symbiose: Strategies and adaptations for the acquisition and fixation of inorganic carbon. Funct. Plant Biol. 2012, 29, 309-322. [CrossRef]

14. Tambutté, É.; Allemand, D.; Mueller, E.; Jaubert, J. A compartmental approach to the mechanism of calcification in hermatypic corals. J. Exp. Biol. 1996, 199, 1029-1041.

15. Tambutte, S.; Tambutte, E.; Zoccola, D.; Caminiti, N.; Lotto, S.; Moya, A.; Allemand, D.; Adkins, J. Characterization and role of carbonic anhydrase in the calcification process of the azooxanthellate coral Tubastrea aurea. Mar. Biol. 2007, 151,71-83. [CrossRef]

16. Ozensoy Guler, O.; Capasso, C.; Supuran, C.T. A magnificent enzyme superfamily: Carbonic anhydrases, their purification and characterization. J. Enzym. Inhib. Med. Chem. 2016, 31, 689-694. [CrossRef] [PubMed]

17. Supuran, C.T. Carbonic anhydrase activators. Future Med. Chem. 2018, 10, 561-573. [CrossRef] [PubMed] 
18. Supuran, C.T. Carbonic anhydrase inhibition and the management of hypoxic tumors. Metabolites 2017, 7, 48. [CrossRef] [PubMed]

19. Supuran, C.T. Structure and function of carbonic anhydrases. Biochem. J. 2016, 473, 2023-2032. [CrossRef] [PubMed]

20. Del Prete, S.; Bua, S.; Zoccola, D.; Alasmary, F.A.S.; AlOthman, Z.; Alqahtani, L.S.; Techer, N.; Supuran, C.T.; Tambutte, S.; Capasso, C. Comparison of the anion inhibition profiles of the $\alpha$-ca isoforms (spica1, spica2 and spica3) from the scleractinian coral Stylophora pistillata. Int. J. Mol. Sci. 2018, 19, 2128. [CrossRef] [PubMed]

21. Del Prete, S.; Vullo, D.; Caminiti-Segonds, N.; Zoccola, D.; Tambutte, S.; Supuran, C.T.; Capasso, C. Protonography and anion inhibition profile of the $\alpha$-carbonic anhydrase (cruca4) identified in the mediterranean red coral Corallium rubrum. Bioorg. Chem. 2018, 76, 281-287. [CrossRef] [PubMed]

22. Del Prete, S.; Vullo, D.; Zoccola, D.; Tambutte, S.; Capasso, C.; Supuran, C.T. Kinetic properties and affinities for sulfonamide inhibitors of an $\alpha$-carbonic anhydrase (cruca4) involved in coral biomineralization in the mediterranean red coral Corallium rubrum. Bioorg. Med. Chem. 2017, 25, 3525-3530. [CrossRef] [PubMed]

23. Del Prete, S.; Vullo, D.; Zoccola, D.; Tambutte, S.; Supuran, C.T.; Capasso, C. Activation profile analysis of cruca4, an $\alpha$-carbonic anhydrase involved in skeleton formation of the mediterranean red coral, Corallium rubrum. Molecules 2017, 23, 66. [CrossRef] [PubMed]

24. Perfetto, R.; Del Prete, S.; Vullo, D.; Sansone, G.; Barone, C.; Rossi, M.; Supuran, C.T.; Capasso, C. Biochemical characterization of the native $\alpha$-carbonic anhydrase purified from the mantle of the Mediterranean mussel, Mytilus galloprovincialis. J. Enzym. Inhib. Med. Chem. 2017, 32, 632-639. [CrossRef] [PubMed]

25. Lomelino, C.L.; Mahon, B.P.; McKenna, R.; Carta, F.; Supuran, C.T. Kinetic and X-ray crystallographic investigations on carbonic anhydrase isoforms i, ii, ix and xii of a thioureido analog of slc-0111. Bioorg. Med. Chem. 2016, 24, 976-981. [CrossRef] [PubMed]

26. Supuran, C.T. Legionella pneumophila carbonic anhydrases: Underexplored antibacterial drug targets. Pathogens 2016, 5, 44. [CrossRef] [PubMed]

27. Supuran, C.T. Carbonic anhydrases-An overview. Curr. Pharm. Des. 2008, 14, 603-614. [CrossRef] [PubMed]

28. Supuran, C.T.; Capasso, C. Biomedical applications of prokaryotic carbonic anhydrases. Expert Opin. Ther. Pat. 2018, 28, 745-754. [CrossRef] [PubMed]

29. Supuran, C.T. Advances in structure-based drug discovery of carbonic anhydrase inhibitors. Expert Opin. Drug Discov. 2017, 12, 61-88. [CrossRef] [PubMed]

30. Capasso, C.; Supuran, C.T. An overview of the carbonic anhydrases from two pathogens of the oral cavity: Streptococcus mutans and Porphyromonas gingivalis. Curr. Top. Med. Chem. 2016, 16, 2359-2368. [CrossRef] [PubMed]

31. Capasso, C.; Supuran, C.T. Bacterial, fungal and protozoan carbonic anhydrases as drug targets. Expert Opin. Ther. Targets 2015, 19, 1689-1704. [CrossRef] [PubMed]

32. Aspatwar, A.; Tolvanen, M.E.; Ortutay, C.; Parkkila, S. Carbonic anhydrase related proteins: Molecular biology and evolution. Subcell. Biochem. 2014, 75, 135-156. [PubMed]

33. Supuran, C.T. Carbonic anhydrases as drug targets-An overview. Curr. Top. Med. Chem. 2007, 7, 825-833. [CrossRef] [PubMed]

34. Supuran, C.T.; Capasso, C. The eta-class carbonic anhydrases as drug targets for antimalarial agents. Expert Opin. Ther. Targets 2015, 19, 551-563. [CrossRef] [PubMed]

35. Capasso, C.; Supuran, C.T. An overview of the selectivity and efficiency of the bacterial carbonic anhydrase inhibitors. Curr. Med. Chem. 2015, 22, 2130-2139. [CrossRef] [PubMed]

36. Capasso, C.; Supuran, C.T. An overview of the $\alpha-, \beta$ - and $\gamma$-carbonic anhydrases from bacteria: Can bacterial carbonic anhydrases shed new light on evolution of bacteria? J. Enzym. Inhib. Med. Chem. 2015, 30, 325-332. [CrossRef] [PubMed]

37. Capasso, C.; Supuran, C.T. Sulfa and trimethoprim-like drugs-Antimetabolites acting as carbonic anhydrase, dihydropteroate synthase and dihydrofolate reductase inhibitors. J. Enzym. Inhib. Med. Chem. 2014, 29, 379-387. [CrossRef] [PubMed]

38. Capasso, C.; Supuran, C.T. Anti-infective carbonic anhydrase inhibitors: A patent and literature review. Expert Opin. Ther. Pat. 2013, 23, 693-704. [CrossRef] [PubMed]

39. Miyamoto, H.; Miyashita, T.; Okushima, M.; Nakano, S.; Morita, T.; Matsushiro, A. A carbonic anhydrase from the nacreous layer in oyster pearls. Proc. Natl. Acad. Sci. USA 1996, 93, 9657-9660. [CrossRef] [PubMed] 
40. Weis, V.M.; Smith, G.J.; Muscatine, L. A $\mathrm{CO}_{2}$ supply'mechanism in zooxanthellate cnidarians: Role of carbonic anhydrase. Mar. Biol. 1989, 100, 195-202. [CrossRef]

41. Marshall, A.T.; Clode, P.L. Effect of increased calcium concentration in sea water on calcification and photosynthesis in the scleractinian coral Galaxea fascicularis. J. Exp. Biol. 2002, 205, 2107-2113. [PubMed]

42. De Boer, M.L.; Krupp, D.A.; Weis, V.M. Two atypical carbonic anhydrase homologs from the planula larva of the scleractinian coral Fungia scutaria. Biol. Bull. 2006, 211, 18-30. [CrossRef] [PubMed]

43. Grasso, L.C.; Maindonald, J.; Rudd, S.; Hayward, D.C.; Saint, R.; Miller, D.J.; Ball, E.E. Microarray analysis identifies candidate genes for key roles in coral development. BMC Genom. 2008, 9, 540. [CrossRef] [PubMed]

44. Bertucci, A.; Innocenti, A.; Zoccola, D.; Scozzafava, A.; Allemand, D.; Tambutte, S.; Supuran, C.T. Carbonic anhydrase inhibitors: Inhibition studies of a coral secretory isoform with inorganic anions. Bioorg. Med. Chem. Lett. 2009, 19, 650-653. [CrossRef] [PubMed]

45. Bertucci, A.; Innocenti, A.; Scozzafava, A.; Tambutte, S.; Zoccola, D.; Supuran, C.T. Carbonic anhydrase inhibitors. Inhibition studies with anions and sulfonamides of a new cytosolic enzyme from the scleractinian coral Stylophora pistillata. Bioorg. Med. Chem. Lett. 2011, 21, 710-714. [CrossRef] [PubMed]

46. Karako-Lampert, S.; Zoccola, D.; Salmon-Divon, M.; Katzenellenbogen, M.; Tambutte, S.; Bertucci, A.; Hoegh-Guldberg, O.; Deleury, E.; Allemand, D.; Levy, O. Transcriptome analysis of the scleractinian coral Stylophora pistillata. PLoS ONE 2014, 9, e88615. [CrossRef] [PubMed]

47. Bhattacharya, D.; Agrawal, S.; Aranda, M.; Baumgarten, S.; Belcaid, M.; Drake, J.L.; Erwin, D.; Foret, S.; Gates, R.D.; Gruber, D.F.; et al. Comparative genomics explains the evolutionary success of reef-forming corals. Elife 2016, 5, e13288. [CrossRef] [PubMed]

48. Voolstra, C.R.; Li, Y.; Liew, Y.J.; Baumgarten, S.; Zoccola, D.; Flot, J.-F.; Tambutte, S.; Allemand, D.; Aranda, M. Comparative analysis of the genomes of stylophora pistillata and acropora digitifera provides evidence for extensive differences between species of corals. Sci. Rep. 2017, 7, 17583. [CrossRef] [PubMed]

49. Drake, J.L.; Mass, T.; Haramaty, L.; Zelzion, E.; Bhattacharya, D.; Falkowski, P.G. Proteomic analysis of skeletal organic matrix from the stony coral Stylophora pistillata. Proc. Natl. Acad. Sci. USA 2013, 110, 3788-3793. [CrossRef] [PubMed]

50. Le Goff, C.; Ganot, P.; Zoccola, D.; Caminiti-Segonds, N.; Allemand, D.; Tambutte, S. Carbonic anhydrases in cnidarians: Novel perspectives from the octocorallian Corallium rubrum. PLoS ONE 2016, 11, e0160368. [CrossRef] [PubMed]

51. Bertucci, A.; Zoccola, D.; Tambutte, S.; Vullo, D.; Supuran, C.T. Carbonic anhydrase activators. The first activation study of a coral secretory isoform with amino acids and amines. Bioorg. Med. Chem. 2010, 18, 2300-2303. [CrossRef] [PubMed]

52. Bertucci, A.; Innocenti, A.; Zoccola, D.; Scozzafava, A.; Tambutte, S.; Supuran, C.T. Carbonic anhydrase inhibitors. Inhibition studies of a coral secretory isoform by sulfonamides. Bioorg. Med. Chem. 2009, 17, 5054-5058. [CrossRef] [PubMed]

53. Marshall, A.T.; Clode, P.L. Light-regulated $\mathrm{Ca}^{2+}$ uptake and $\mathrm{O}_{2}$ secretion at the surface of a scleractinian coral Galaxea fascicularis. Comp. Biochem. Physiol. A 2003, 136, 417-426. [CrossRef]

54. Weis, V.M. Effect of dissolved inorganic carbon concentration on the photosynthesis of the symbiotic sea anemone aiptasia pulchella carlgren: Role of carbonic anhydrase. J. Exp. Mar. Biol. Ecol. 1993, 174, $209-225$. [CrossRef]

55. Supuran, C.T. How many carbonic anhydrase inhibition mechanisms exist? J. Enzym. Inhib. Med. Chem. 2016, 31, 345-360. [CrossRef] [PubMed]

56. Supuran, C.T. Carbonic anhydrase inhibition and the management of neuropathic pain. Expert Rev. Neurother. 2016, 16, 961-968. [CrossRef] [PubMed]

57. Supuran, C.T. Drug interaction considerations in the therapeutic use of carbonic anhydrase inhibitors. Expert Opin. Drug Metab. Toxicol. 2016, 12, 423-431. [CrossRef] [PubMed]

58. Supuran, C.T. Acetazolamide for the treatment of idiopathic intracranial hypertension. Expert Rev. Neurother. 2015, 15, 851-856. [CrossRef] [PubMed]

59. Edgar, R.C. Muscle: Multiple sequence alignment with high accuracy and high throughput. Nucleic Acids Res. 2004, 32, 1792-1797. [CrossRef] [PubMed]

60. Khalifah, R.G. The carbon dioxide hydration activity of carbonic anhydrase. I. Stop-flow kinetic studies on the native human isoenzymes b and c. J. Biol. Chem. 1971, 246, 2561-2573. [PubMed] 
61. Del Prete, S.; Vullo, D.; De Luca, V.; Carginale, V.; di Fonzo, P.; Osman, S.M.; AlOthman, Z.; Supuran, C.T.; Capasso, C. Anion inhibition profiles of $\alpha-, \beta$ - and $\gamma$-carbonic anhydrases from the pathogenic bacterium vibrio cholerae. Bioorg. Med. Chem. 2016, 24, 3413-3417. [CrossRef] [PubMed]

62. Del Prete, S.; Vullo, D.; De Luca, V.; Carginale, V.; di Fonzo, P.; Osman, S.M.; AlOthman, Z.; Supuran, C.T.; Capasso, C. Anion inhibition profiles of the complete domain of the $\eta$-carbonic anhydrase from Plasmodium falciparum. Bioorg. Med. Chem. 2016, 24, 4410-4414. [CrossRef] [PubMed]

63. De Luca, V.; Vullo, D.; Del Prete, S.; Carginale, V.; Osman, S.M.; AlOthman, Z.; Supuran, C.T.; Capasso, C. Cloning, characterization and anion inhibition studies of a $\gamma$-carbonic anhydrase from the antarctic bacterium colwellia psychrerythraea. Bioorg. Med. Chem. 2016, 24, 835-840. [CrossRef] [PubMed]

64. Sterling, D.; Reithmeier, R.A.; Casey, J.R. Carbonic anhydrase: In the driver's seat for bicarbonate transport. J. Pancreas 2001, 2, 165-170.

65. Sterling, D.; Reithmeier, R.A.; Casey, J.R. A transport metabolon. Functional interaction of carbonic anhydrase ii and chloride/bicarbonate exchangers. J. Biol. Chem. 2001, 276, 47886-47894. [CrossRef] [PubMed]

66. McMurtrie, H.L.; Cleary, H.J.; Alvarez, B.V.; Loiselle, F.B.; Sterling, D.; Morgan, P.E.; Johnson, D.E.; Casey, J.R. The bicarbonate transport metabolon. J. Enzym. Inhib. Med. Chem. 2004, 19, 231-236. [CrossRef] [PubMed]

67. Rogato, A.; Del Prete, S.; Nocentini, A.; Carginale, V.; Supuran, C.T.; Capasso, C. Phaeodactylum tricornutum as a model organism for testing the membrane penetrability of sulphonamide carbonic anhydrase inhibitors. J. Enzym. Inhib. Med. Chem. 2019, 34, 510-518. [CrossRef] [PubMed]

(C) 2019 by the authors. Licensee MDPI, Basel, Switzerland. This article is an open access article distributed under the terms and conditions of the Creative Commons Attribution (CC BY) license (http:/ / creativecommons.org/licenses/by/4.0/). 